\title{
Educación Social e Educación
}

Ambiental: Análise de propostas

ambientais nas carreiras de montaña

Social Education and Environmental Education:

environmental proposal's analysis in mountain races

Javier Villaverde Doval. Universidade da Coruña (Galiza-España)

\begin{abstract}
Resumo
A educación social e a educación ambiental perseguen o benestar da sociedade actual e das futuras. $O$ interese deste traballo centrase no impacto do deporte, mais concretamente as carreiras de montaña no medio natural. A metodoloxía seguida no traballo responde á investigación cualitativa a través da análise documental de fontes primarias e secundarias. $A$ motivación deste tema débese o aumento do número de corredores de montaña, o cal ten unha tendencia clara nos últimos anos. EUROPARC-España calcula que cerca de 700.000 persoas corren anualmente por espazos naturais singulares. Analizarase os documentos que regulan este tipo de actividades para identificar propostas de conservación e solucións para o impacto provocado polas carreiras de montaña: Protocolo Medioambiental da FEDME, Manual sobre deporte e medio ambiente do COI, Proposta e accións da Estratexia Nacional sobre Deporte e Sustentabilidade, Propostas de medidas de xestión ambiental para a sustentabilidade das carreiras por montaña en espazos naturais protexidos da UAM e Manual 12 de EUROPARC-España: Guía de boas prácticas para desenvolvemento de carreiras por montaña en espazos naturais protexidos.
\end{abstract}

\section{Astract}

Social education and environmental education pursue the welfare of today's society and of the future. The interest of this work focuses on the impact of sport, but specifically mountain races in the natural environment. The methodology followed in the work responds to qualitative research through the documentary analysis of primary and secondary sources. The motivation of this subject is due to the increase in the number of mountain corridors, which has a clear tendency in recent years. EUROPARC-Spain estimates that around 700,000 people run annually by unique natural spaces. The documents that regulate this type of activities will be analyzed to identify conservation proposals and solutions for the impact caused by mountain races:Protocolo Medioambiental da FEDME, Manual sobre deporte e medio ambiente do COI, Proposta e accións da Estratexia Nacional sobre Deporte e Sustentabilidade, Propostas de medidas de xestión ambiental para a sustentabilidade das carreiras por montaña en espazos naturais protexidos da UAM e Manual 12 de EUROPARC-España: Guía de boas prácticas para desenvolvemento de carreiras por montaña en espazos naturais protexidos.

\section{Palabras chave}

Educación Social, Protocolo, Carreiras de Montaña, Sustentabilidade

\section{Key-words}

Social Education, Protocol, Mountain Races, Sustainability 


\section{Introdución}

A educación social ten un papel importante na sociedade, loitando polo benestar social. Unha das areas da educación social, na cal centrase o presente traballo, é a Educación ambiental sendo esta "(...) unha disciplina cuxa intervención debe ter en conta os aspectos educativos e sociais xa que as persoas, os grupos e as comunidades son os afectados e beneficiarios das transformacións no medio ambiente" (AmAdOR MuÑOz \& Esteban IBÁNEZ, 2011, p.157).

O interese deste traballo centrase no impacto do deporte, mais concretamente as carreiras de montaña no medio natural, xa que como ben apuntan AmAdOR MuÑOz e EsTEBAN IBÁÑEZ (2011) os impactos ambientais e sociais teñen orixes moi diversos.

É preciso coñecer como se regulan estas actividades e que medidas se están a levar a cabo para conseguir unha práctica deportiva das carreiras de montaña sustentable para o medio natural e social.

\section{Obxectivos e metodoloxía}

A través da análise dos protocolos que regulan as carreiras de montaña, búscase:

- Visibilizar o papel da educación social na educación ambiental
- Coñecer os factores que favorecen ó aumento das carreiras de montaña

- Destacar o papel da educación e da necesidade de sensibilización ambiental para reducir seu impacto

- Dar a coñecer os axentes do binomio deporte e natureza e a responsabilidade que teñen co medio natural

- Destacar a presenza do binomio deporte e natureza na lexislación, normativas e regulamentos

- Coñecer distintas propostas e protocolos medioambientais nas carreiras de montaña

Optamos por realizar unha investigación de corte cualitativo de análise de contido, a través da análise documental de fontes primarias e secundarias. Para o seu desenvolvemento seguiuse as técnicas que recolle FLICK (2007, p.207-208):

- Resumo do análise do contido

- Análise explicativo do contido

- Análise estrutúrante do contido

\section{Referentes teóricos}

A educación social e a educación ambiental perseguen o benestar da sociedade actual e das futuras xeracións, e "o reto das dúas será (...) o de promover unha nova relación da sociedade humana ca natureza, a fin de procurar as xeracións actuais e futuras un desenvolvemento per- 
soal e colectivo máis xusto, equitativo e sustentable, que poida garantir a conservación do soporte físico-biolóxico sobre o que se sustenta. O desafío é ante todo, conseguir unha educación para a acción social, educativa e ambiental" (Amador MuÑoz \& Estaban IBÁÑEZ, 2011, p.151).

Os documentos marco de referencia sobre Educación Ambiental no contexto galego son o Libro Blanco de la Educación Ambiental en España e a Estratexia Galega de Educación Ambiental; ambos os dous definen os fins, obxectivos e retos nos distintos ámbitos de actuación no contexto estatal e autonómico.

O Libro Blanco de la Educación Ambiental en España (1999) asume como propia a definición de Educación Ambiental dada no Congreso Internacional de Educación e Formación sobre Medio Ambiente en Moscú, no ano 1987:

\begin{abstract}
"A educación ambiental é un proceso permanente no cal os individuos e as comunidades adquiren conciencia do seu medio e aprenden os coñecementos, os valores, as destrezas, a experiencia e tamén a determinación que Iles capacite para actuar, individual e colectivamente, na resolución dos problemas ambientais futuros" (p.6).
\end{abstract}

Pola súa parte, na Estratexia Galega de Educación Ambiental (2000) se define como: "unha dimensión da educación integral e global das persoas e colectividades sociais, que na súas diversas manifestacións e prácticas, promove o coñecemento, interpretación e concienciación respecto das diferentes problemáticas ambientais, do seu impacto local e planetario, activando competencias e valores dos que se deriven actitudes e comportamento congruentes coa ética ecolóxica que se precisa para participar na construción dun desenvolvemento humano sustentable". (p.16)

Ambas as dúas definicións fan fincapé na necesidade de adquirir coñecementos e competencias que nos permita solucionar os problemas ambientais mediante un desenvolvemento sustentable.

$\mathrm{Na}$ actualidade, os organismos internacionais teñen substituído no seu discurso o concepto de Educación Ambiental polo de Educación para o Desenvolvemento Sustentable, como destaca Michela MAYER cando di que "o primeiro desafío ó que se enfronta a educación nos anos 2000 é por tanto o de reconsiderar criticamente o que significou, e que pode significar no futuro, a indicación de Río de reorientar a educación ambiental cara a educación para o desenvolvemento sustentable" (Michela MAYER, 2003, p.2).

Isto acentúase tras o acordo do 25 de setembro de Nacións Unidas (2015) na Axenda 2030 para o Desenvolvemento Sostible que recibe o nome de Obxectivos de De- 
senvolvemento sostible, na que se define o desenvolvemento sostible como un xeito de conseguir "un mundo onde sexan sostibles as modalidades de consumo e produción e a utilización de tódolos recursos naturais (...)" conseguindo un equilibrio entre economía, sociedade e ambiente.

\section{Deporte e natureza:}

\section{carreiras de montaña}

Actualmente o deporte ten unha gran presenza na sociedade Española e Galega, se temos en conta a evolución que tivo nestes últimos anos. Proba disto son os datos proporcionados desde o Ministerio de Educación Cultura e Deporte (2016) (Gráficas 1 e 2).

Chama a atención a tendencia de aumento que segue tanto en España como en Galicia as porcentaxes nas gráficas 1 e 2, sendo especialmente relevante o aumento tan grande nas practicas deportivas realizadas por mulleres.

Para observar a evolución sobre a práctica deportiva no medio natural en España, tomamos como referencia a evolución do número de Federados en actividades de Montaña e Escalada, segundo datos do Ministerio de Educación Cultura e Deporte (2016) (Gráfica 3):

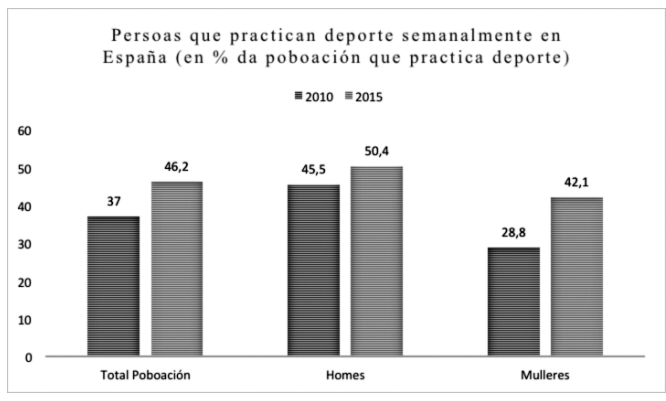

Gráfica 1: Persoas que practican deporte semanalmente en España

Fonte: Ministerio de Educación Cultura e Deporte (2016)

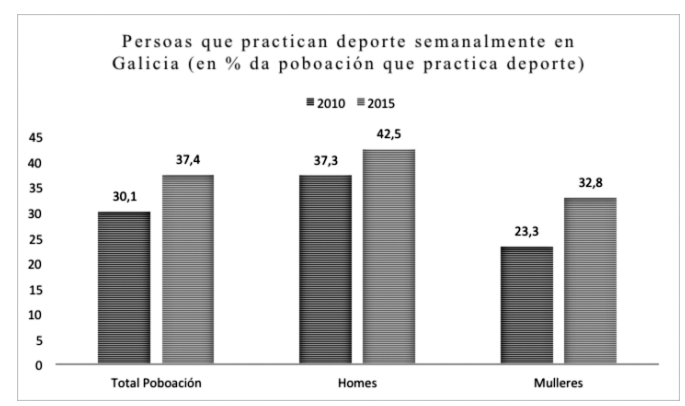

Gráfica 2: Persoas que practican deporte semanalmente en Galicia

Fonte: Ministerio de Educación Cultura e Deporte (2016)
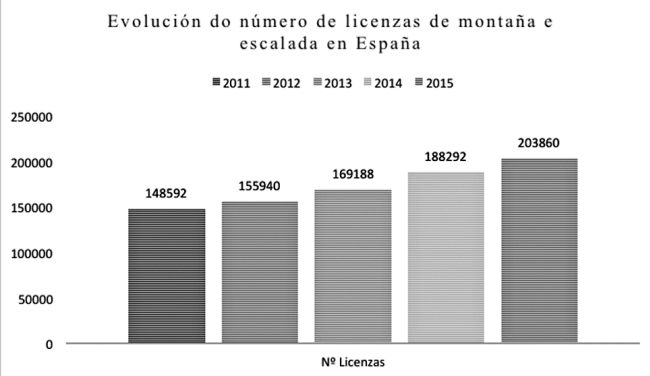

Gráfica 3: Evolución do número de licenzas de montaña e escalada en España Fonte: Ministerio de Educación Cultura e Deporte (2016) 
Vemos claramente na gráfica 3 como entre 2011 e 2015 aumentou até 55.268 o número de licenzas en España. Salientar que no ano 2015 en Galicia 4.064 persoas tiñan este tipo de licenza, en torno a 74 clubes. Estes datos non contemplan aquelas persoas non federadas e/ou esporádicas, co cal temos que ter en conta que o aumento da práctica deportiva na natureza é maior do que indican estes datos.

A modalidade deportiva na que nos centramos serán as carreiras de montaña, xa que están a cobrar gran relevancia polo auxe das carreiras populares. As carreiras de montaña son as que se realizan correndo a pé por espazos naturais, onde a montaña é o eixo central. En relación ao número de corredores de montaña no ano 2015 segundo datos EUROPARCA-España (2016, p.18) "se calcula que cerca de 700.000 persoas corren anualmente por espazos naturais singulares. Isto da idea da importancia do fenómeno."

O auxe desta disciplina podería poñer en risco os espacios naturais nos que se practica. Neste sentido, Luque Gil sinala que "unha adecuada utilización dos recursos non pasa por unha prohibición a ultranza dos usos dentro do espazo (...)" (2003, p.143). É preciso unha concienciación de todos os axentes involucrados nestas práctica deportiva, e é aquí onde o papel da educación (ambiental) é vital.

\section{Evolución da relevancia da sustentabilidade e do binomio deporte-medio ambiente}

A presenza do binomio deporte-medio ambiente foi evolucionando dende 1972, cando o Clube de Roma publica un primeiro informe titulado Os límites do crecemento no "que expresaba preocupación polo crecemento da poboación mundial e os recursos naturais finitos" (PNUMA, s.d., p.6). Neste ano, a ONU realiza unha conferencia sobre o Medio na cal se recolle que "o home ten a responsabilidade especial de preservar e administrar xuizosamente o patrimonio" (NACIÓNS UNIDAS, 1972).

No ano 1987, a Comisión Brundtland acuña o concepto de desenvolvemento sustentable no informe coñecido como Noso Futuro Común (PNUMA, s.d. , p.6) que foi exposto na Comisión Mundial sobre o Medio Ambiente e o Desenvolvemento da ONU.

Mais será no ano 1992 cando a ONU en Río '92 aproba a Axenda 21, "un programa para o enfoque equilibrado e integrado cara os asuntos de medio ambiente e desenvolvemento para o século XXI" (PNUMA, s.d. , p.6). Neste mesmo ano, a UE publica a Carta Europea do Deporte, a cal fai referencia directa ao binomio deporte-medio ambiente e que entre as súas me- 
didas recolle o de "tomar en consideración os valores da natureza e medio ambiente" (UNIÓN EUROPEA, 1992, p.13).

No ano 1995 se forma a Comisión para o Deporte e Medio Ambiente do Comité Olímpico Internacional e no ano 1996 "a Carta Olímpica adopta o medio ambiente como o terceiro pilar do Olimpismo, xunto co deporte e a cultural" (COMItÉ OLímPICo INTERNACIONAL, 2016, p.17).

No ano 2000 a ONU impulsa $A$ Carta da Terra onde sinala que "debemos unirnos para crear unha sociedade global sustentable fundada no respecto cara a natureza, os dereitos humanos universais, a xustiza económica e unha cultura de paz" (Nacións Unidas, 2000, p.1).

No ano 2003 o PNUMA elabora a Estratexia de longo prazo sobre o Deporte e Medio Ambiente, coñecida como a Estratexia Michezo, na cal "(...) se establece unha colaboración estreita con tódolos socios e se alenta ós gobernos a promover cuestións relativas ó deporte e o medio ambiente" (Green Cross-España, 2007b, p.11). No ano 2005 o COI publica o Manual sobre deporte e medio ambiente.

Será no ano 2007 no que a Unión Europea publica o Libro Branco sobre o Deporte, documento especialmente relevante polo apoio ó desenvolvemento sustentable da practica deportiva no medio natural. Este mesmo ano publicase tamén a primeira referencia en España ó deporte e sustentabilidade -a Carta Verde do Deporte Español-, proposta do Consello Superior de Deportes ca colaboración de Green Cross-España. A partir desta Carta Verde do Deporte Español redactarase a Estratexia Nacional sobre Deporte e Sustentabilidade.

Por último, destacar que desde e ano 2012 "o Movemento Olímpico está sumamente involucrado no desenvolvemento da ISO 20121, un estándar internacional para axudar ós organizadores a preparar un plan dos impactos económicos, ambientais e sociais dos eventos" (PNUMA, s.d., p.8)

\section{Axentes implicados no deporte na natureza}

O mais habitual é pensar unicamente nos deportistas e nos organizadores dos eventos, pero a realidade é máis ampla, como ben mostra Green Cross-España (2007b) no terceiro apartado da Estratexia Nacional sobre Deporte e Sustentabilidade e que son os seguintes:

Organismos Olímpicos:

- Comité Olímpico Internacional

- Comité Olímpico Nacional - Comité Olímpico Español

Organismos Deportivos:

- Federacións Internacionais: 
- International Skyrunning Federation

- Interantional Trail Running Association

- Federacións Nacionais:

- Real Federación Española de Atletismo

- Federación Española de Deportes de Montaña e Escalada

- Asociación Española de Trail

- Federacións Autonómicas:

- Federación Galega de Montaña

- Clubes/Asociacións

- Deportistas

- Espectadores

- Voluntariado

Administracións Publicas

- Nacións Unidas-PNUMA. Programa das Nacións Unidas para o Medio Ambiente

- Unión Europea

- Goberno Estatal-Consello Superior do Deporte

- Comunidades Autónomas

- Organismos Locais, Municipios e Provincias

\section{Outros Organismos}

- Empresas Sector Turístico

- Sector privado e industria do deporte, nivel internacional e nacional

- Empresas que interaccionan con actividades deportivas na subministración de servicios

- Organizacións Sociais e ONGs

- Centros de formación e xestión deportiva

- Medios de Comunicación
- Centros de investigación e profesionais

Organismos de Deporte Sustentable

- Global Sports Alliance

- The Athens Environmental Foundation

- Go for green

- Green \& Gold Inc.

\section{Contexto lexislativo, nacional e autonómico do binomio deporte e medio ambiente}

Destaca a desregulación existente sobre as carreiras de montaña no ámbito lexislativo. Os referentes son escasos e pouco normativos, como a Lei 10/1990 do deporte en España, a cal só recolle como competencia propia a de colaborar en materia de medio ambiente e defensa da natureza con outros organismos públicos e Federacións, ou a Lei 3/2012 do deporte de Galicia, a cal é algo máis completa, quizás por ser máis recente que a española. Nesta última recóllense funcións que o deporte desempeña na sociedade, en concreto no artigo 2, facendo fincapé "na educación, formación, cultura e medio ambiente entre outros", no artigo 3 no que destaca a consecución dunha práctica deportiva con valores de preservación do medio ambiente e a sustentabilidade e nos artigos 4 e 5 nos que destaca a adecuada utilización do medio natural e protección do medio du- 
rante a practica deportiva. Tamén no artigo 14 se fai referencia directa a actividade deportiva no medio natural, destacando o respecto ó medio natural como obxectivo principal das políticas deportivas Galegas, facendo da Administración autonómica a responsable de promover a existencia de información actualizada do réxime e dos requisitos necesarios para a práctica deportiva no medio natural, así como as limitacións e restricións para esta, a fin de favorecer a práctica de modalidades deportivas que se desenvolvan nel.

Referente ó ámbito ambiental, a lexislación apenas recolle medidas xerais de uso dos espazos, e sen prestar especial atención as actividades deportivas no medio natural. En concreto, no ámbito nacional vemos como a Lei 43/2003 española de montes non fai ningunha referencia ó relativo ó deporte como posible xerador de impacto no medio natural, ou como a Lei 21/2013 de avaliación ambiental en España, dentro dos proxectos sometidos á avaliación ambiental, contemplase as pistas permanentes de carreiras e de probas para vehículos motorizados, mais non vemos ningunha referencia as carreiras de montaña, as cales non se teñen en conta. No referente ás leis autonómicas vemos como a Lei 7/2012 de montes en Galicia ten en conta medidas relativas as actividades deportivas no monte, en concreto o Artigo 84 no que inclúe o deporte como un dos servizos característicos do monte ou o Artigo 88 que cita os eventos deportivos a motor, onde o promotor será o responsable de toda incidencia, dano ou prexuízo que puidera producirse, mais non hai referencia algunha ás carreiras de montaña.

Finalmente no relativo ó turismo deportivo vemos como o Decreto 42/2001, en materia de axencias de viaxes, guías de turismo e turismo activo de Galicia recolle no artigo 42, sobre as empresas de turismo, sendo estas as que teñen actividades que se practique servíndose dos recursos que ofrece a propia natureza.

\section{Opinión das redes sociais: presencia da educación ambiental nas carreiras}

Todos os meses, o día 26 entre as 18 e 19 horas, atópanse en Twitter "persoas ocupadas e preocupadas" na educación ambiental co hashtag \#EA26 (https://educacionambiental26. wordpress.com/). 026 de maio de 2017 xerouse nesta rede social un debate co tema "Está presente a Educación Ambiental nos eventos deportivos?". O longo desa hora xurdiron reflexións como os seguintes:

- Coñecemento dalgún evento deportivo que teña en conta aspectos ambientais: a maioría das respostas foron negativas. Algén fixo mención a un evento no que se calculaba a súa pegada de carbono. 
- Proba deportiva con educadores ambientais: a resposta volve a ser negativa, coa excepción dun usuario que pon un enlace á Federación de montaña de Madrid, ó apartado de informes das carreiras.

- A educación ambienta debería estar presente na organización

- A xestión ambiental dos evento debería centrarse nos residuos

- Só se hai intención educativa, hai educación ambiental: o que algúns usuarios planean engadilo como norma para os eventos deportivos

- Os eventos deportivos non teñen fins educativos

- A masificación das probas xera conflito entre o uso e a protección da natureza

- Algunhas posibles solucións:

- Participantes amantes da natureza

- Figura do Xestor ambiental

- Exixir avaliacións do impacto ambiental e educación ambiental antes, durante e despois do evento

- Destinar parte da inscrición á educación ambiental dos participantes

- Algunhas conclusións:

- Déficit de Educación Ambiental en eventos deportivos

- Dous tipos de receptores:

- Participantes

- Organizadores

- Facer visibles os impactos das probas na natureza

- Se trata de eventos onde a Educación Ambiental pode ter lugar.

\section{Análise de propostas ambientalmente sostibles para as carreiras de montaña}

Presentamos os documentos que recollen propostas ambientalmente sostibles para as carreiras de montaña, nas cales se atopan distintas solucións para o impacto provocado polas carreiras de montaña:

- Protocolo Medioambiental da FEDME (Federación Española de Deportes de Montaña e Escalada, 2002)

- Manual sobre deporte e medio ambiente do COI (COMité Olímpico InTERnAcIonal, 2005)

- Proposta e accións da Estratexia Nacional sobre Deporte e Sustentabilidade (Green Cross-España, 2007b)

- Propostas de medidas de xestión ambiental para a sustentabilidade das carreiras por montaña en espazos naturais protexidos da UAM (Benayas, Oñobre \& HorCajo, 2015)

- Manual 12 de EUROPARC-España: Guía de boas prácticas para desenvolvemento de carreiras por montaña en espazos naturais protexidos. (EUROPARC-España, 2016)

Despois de analizar as propostas ambientais destes documentos, só podemos considerar as de EUROPARC-España e a FEDME como instrumentos útiles neste sentido, xa que son as mais completas in- 
cluíndo accións como o respecto a lexislación -recollido na proposta da FEDME- e o impacto socioeconómico -recollido na proposta de EUROPARC-España- entre o resto de medidas necesarias para o control do impacto das carreiras de montaña.

A proposta de Green Cross-España é significativamente mellorable xa que obvia tódolos elementos referidos ao control do impacto, ao trazado de carreira, ás funcións dos actores e ás medidas de respecto, control ou sanción; unicamente céntrase na sensibilización.

O COI e a UAM, aínda que conteñen propostas xerais en case a totalidade de campos, non chegan a tratar tódalas accións necesarias.

\section{Conclusións}

Unha vez revisado o estado da cuestión, pódese destacar que a relación da educación social con respecto a educación ambiental é moi forte xa que ambas perseguen o benestar da sociedade. A educación social ten a posibilidade de xerar accións que propicien o coidado e a sensibilización ambiental.

A tendencia de incrementarse o número de corredores de montaña é indiscutible. Os factores principais son: a tendencia de aumento da practica deportiva xeral nos últimos anos -especialmente nas mulleres-, o feito de ter beneficios económicos e o turismo deportivo.

Respecto ó aumento de corredores, cobra especial relevancia introducir programas de educación ambiental neste ámbito, xa que como vimos a practica deportiva por si mesma non sensibiliza, é existe un gran risco de xerar impactos na natureza.

No relativo ós axentes presentes no binomio deporte e natureza, é vital o papel das Organizacións Internacionais para un desenvolvemento sustentable nas carreiras de montaña, organizacións como o $\mathrm{COI}$-por ter un maior protagonismo na difusión de valores ambientais-, xunto a ONU -con especial atención na PNUMAe a UE -tanto por elaborar os documentos de referencia en canto a sustentabilidade e deporte, como pola súa influencia nos distintos estados que a conforman-. A nivel nacional, aínda queda moito traballo por parte de institucións relacionadas co deporte, o turismo e o medio ambiente.

É preciso a regulación e o control destas actividades, polo que resulta preocupante a carencia dun marco lexislativo. O Estado non parece estar a favor de traballar por un desenvolvemento sustentable, xa que delega esta responsabilidade nos municipios. A pouca normativa existente, limitase a recomendar a colaboración con outras institucións ou dar medidas xerais do uso complementario do medio. 
Despois de realizar a análise das distintas propostas de ambientalización das carreiras de montaña, queremos destacar a FEDME e EUROPARC-España: son os dous organismos que proporcionan instrumentos útiles neste sentido, xa que son os mais completos e abarcan tódolos momentos (antes, durante e despois), ademais de incluír accións como o respecto a lexislación -aínda por desenvolver- e contempla o impacto socioeconómico sobre a poboación local.

No referido ao papel da educación social, esta podería ter unha maior presenza no ámbito da Educación para o Desenvolvemento Sustentable, xa que os seus profesionais son competentes en ámbitos como a mediación social, cultural e educativa.; tamén pola capacidade de traballo interdisciplinar e cooperativo propio da educación social.

\section{Propostas de mellora}

\section{Proposta 1: Actualizar a lexislación en materia de deporte e natureza}

O aumento da demanda/práctica do deporte no medio natural esixe revisar e modificar urxentemente a lexislación vixente, para que contemple medidas reductoras dos factores que producen impacto ne- gativo, incidindo en modalidades como as carreiras de montaña,

A lei 10/1990 do Deporte en España precisa que se inclúa nalgún dos seus apartados aspectos como:

- el deporte como unha práctica sustentable no medio natural

- medidas para minimizar o impacto no medio das carreiras de montaña

- medidas nos eventos deportivos que propicien a mellora do entorno natural e social da zona pola que discorra o recorrido.

\section{Proposta 2: Crear a figura do Educador Socio-Ambiental nas institucións públicas}

Dentro das administracións públicas é interesante contar ca figura de educador socio-ambiental, encargado de formar e fomentar o desenvolvemento sustentable na poboación e nas organizacións.

Existen oportunidades en moitas das institucións relacionadas co medio ambiente. Por exemplo, e seguindo as liñas establecidas na Estratexia Paisaxe Galega da Xunta de Galicia (2011):

- Liña 1: Redacción dos instrumentos de protección, ordenación e xestión das paisaxes

Crear catálogos e directrices paisaxísticas das distintas rexións de Galicia onde 
se realizan as carreiras de montaña, tendo en conta a tódalas persoas, entidades públicas e privadas interesadas no entorno natural.

\section{- Liña 2: Integración paisaxística}

Elaborar manuais de boas prácticas -ou empregar algunha de referencia- para orientar ás administracións, ás organizacións e ós cidadáns/corredores no desenvolvemento sustentable. No caso das carreiras de montaña, co emprego dunha Guía de boas prácticas para as organizacións.

- Liña 3: Sensibilización, formación e divulgación da paisaxe

É vital incluír na ensinanza formal, materias de sensibilización ambiental e desenvolvemento sustentable, en especial naquela formación especificamente deportiva e/ ou de xestión do espazo natural, para fomentar prácticas de mellora e coidado nas súas practicas e que repercutan positivamente tanto no entorno natural como no social.

A educación fóra do sistema educativo formal tamén xoga un papel, tanto ou mais importante, no ámbito deportivo. Resulta pertinente fomentar a realización de cursos de formación ambiental e de desenvolvemento sustentable, con especial fincapé na súa aplicación no deseño de carreiras de montaña. As administracións poden realizar cursos de Xestión Ambiental para que o Clubes e organizadores dos eventos deportivos. Os educadores socio- ambientais son os preofesionais con competencia suficiente para a súa realización.

\section{Referencias bibliográficas}

AMADOR MUÑOZ, L. V., e ESTABAN IBÁÑEZ, M. (2011). Desde la educación social a la educación ambiental. Hacía una intervención educativa socioambiental. Revista de Humanidades, 18, 147-160.

BENAYAS, J., OÑOBRE, M. E HORCAJO, L. (2015). Propuesta de Medidas de Gestión Ambiental para la Sostenibilidad de las Carreras por Montaña en Espacios Naturales Protegidos. Universidade Autonoma de Madrid.

BOLETíN OFICIAL DEL ESTADO (1990). Ley 10/1990, de 15 de octubre, del Deporte. Madrid, 17 de octubre de 1990, núm 249, pp. 30397-30411

BOLETÍN OFICIAL DEL ESTADO (2003). Ley 43/2003, de 21 de noviembre, de Montes. Madrid, 22 de noviembre de 2003, núm 280, pp. 41422 - 41442

BOLETÍN OFICIAL DEL ESTADO (2013). Ley 21/2013, de 9 de diciembre, de evaluación ambiental. Madrid, 11 de diciembre de 2013, núm 296, pp.98151 - 98227

COMITÉ OLÍMPICO INTERNACIONAL (2005). Manual sobre Deporte y Medio Ambiente.

COMITÉ OLÍMPICO INTERNACIONAL (2016). Olympic Charter. Lausanne: International Olympic Committee.

DIARIO OFICIAL DE GALICIA (2001). Decreto 42/2001, de 1 de febrero, de refundición en materia de agxencias de viaxes, guías de turismo e turismo activo. Santiago de Compostela, 20 de febreiro de 2001, núm 36, pp.2222

DIARIO OFICIAL DE GALICIA (2012). Lei 3/2012, de 2 de abril, do deporte de Galicia. Santiago de Compostela, 13 de abril de 2012, núm 71, pp.13194

DIARIO OFICIAL DE GALICIA (2012). Lei 7/2012, do 28 de xuño, de montes de Galicia. Santiago de Compostela, 23 de xullo de 2012, núm.140, pp.29234

EUROPARC-España (2016). Guía de buenas prácticas para el desarrollo de carreras por montaña en espacios naturales. Manual 12 Series de manuales EUROPARC-España. Madrid: Fundación Fernando González Bernáldez. 
FEDERACIÓN ESPAÑOLA DE DEPORTES DE MONTAÑA Y ESCALADA. (2002). Protocolos de control ambiental.

FLICK, U. (2007). Introducción a la investigación cualitativa. Madrid: Ediciones Morata, S.L.

GREEN CROSS-España. (2007a). Carta Verde del Deporte Español.

GREEN CROSS-España. (2007b). Estrategia Nacional sobre Deporte y Sostenibilidad.

LUQUE GIL, A. M. (2003). La evaluación del medio para las prácticas de actividades turístico-deportivas en la naturaleza. En Cuadernos de Turismo 12, pp. 131-149.

MAYER, M. (2003). Nuevos retos para la Educación Ambiental. Centro Nacional de Educación Ambiental.

MINISTERIO DE MEDIO AMBIENTE. (1999). Libro Blanco de la Educación Ambiental en España. Madrid: Ministerio de Medio Ambiente.

MINISTERIO DE EDUCACIÓN, CULTURA Y DEPORTE (2016). Anuario de Estadísticas Deportivas 2016. Secretaría General Técnica.

NACIÓNS UNIDAS (1972). Informe de la Conferencia de las Naciones Unidas sobre el Medio Humano. Nueva York: Naciones Unidas.

NACIÓNS UNIDAS (2000). La Carta de la Tierra.

NACIÓNS UNIDAS (2015). Proyecto de documento final de la cumbre de las Naciones Unidas para la aprobación de la agenda para el desarrollo después de 2015.

PEREIRA CORDIDO, J. M., GUTIERREZ ROGER, X. e RODRÍGUEZ ROGINA, A. (2000). Estratexia Galega de Educación Ambiental. Santiago: Xunta de Galicia.

PNUMA. (s.d.). Un desarrollo sostenible y las Olimpiadas (1972-2012). TUNZA. Tomo 10 No 1, 6-8.

UNIÓN EUROPEA (1992). Carta Europea del Deporte.

UNIÓN EUROPEA (2007). Libro Blanco sobre el deporte.

XUNTA DE GALICIA (2011). Estratexia Paisaxe Galega. 